\title{
MKUNYA AN EXPERIMENT IN LEPROSY CONTROL
}

by J. E. J. Hurman, M.B., B.S.(L.OND.), D.T.M. \& H.(ENG.)

"Public expenditure on national health is like expenditure on a life-boat or a fire-engine; even more it is like a long term investment. It yields its interest with absolute certainty, a thousand-fold, but only in the course of years and sometimes in the course of generations. It is money hidden in maternity, in good schools, in pure food, in clean streets, in sanitary houses, in an abundant water supply, in dispensaries, hospitals and sanatoria, and in the vast network of a sanitary and protective cordon in every village and city of the land. Its efforts are unappreciated until they are withdrawn. Yet without this investment the nation is bankrupt".-SIR GeOrge Newman: Annual Report of the Chief Medical Officer of the Ministry of Health, 1921.

\section{Leprosy Incidence in Southern Tanganyika}

The Southern Province of Tanganyika stretches across the width of the Territory from the shore of Lake Nyasa to the Indian Ocean, and is adjacent to Portuguese East Africa. It occupies an area of 55,223 square miles (about 143,000 sq. kilom.).

In 1950 the Interterritorial Leprologist to the East African High Commission surveyed 36 samples of the population of the Province, numbering 884,679 persons at that time. (Ross Innes 1950). 1,384 cases of leprosy were found in 52,214 persons examined, giving an incidence of 26.5 per thousand. The incidence was highest in Newala District (35 per thousand) and Masasi District (30.8 per thousand), both of which Districts lie to the eastern end of the Province. It was estimated that 8,900 cases of leprosy existẹd within these two Districts.

Treatment for the disease was being provided by the medical services of two Missions working in these Districts. The Benedictine Mission at Ndanda in Masasi District was treating 600 patients at its Leprosarium, and the Universities' Mission to Central Africa was running a chain of 15 outpatient clinics centred on the previous work of Miss Edith Shelley at Lulindi, also in Masasi District and treating a total of 2,000 patients. Hydnocarpus injections were the standard treatment at both Missions, although sulphetrone had been tried in 5 cases at Ndanda with good results.

Ross Innes recommended that the leprosarium at Ndanda should be enlarged and that a secnod leprosarium should be opened near the Masasi-Newala border, with initial residential accommodation for 100 patients, but capable of expansion to accommodate 1,000 patients. He thought that such a leprosarium could become self- 
supporting on the produce obtained as the result of work by the residents, but in view of the interest shown by the Native Authorities of the Districts, these Authorities should be asked to contribute towards the capital cost of the construction and assist in the maintenance of the colony until such a point had been reached.

\section{The Early Days of Mkunya Leprosarium}

A suitable site was found at Mkunya, in the south-western corner of the Makonde Plateau, lying 12 miles (about $19 \mathrm{~km}$.) from the Newala District Headquarters and about 1,000 ft. (304 m.) above the Ruvuma River, which flows 3-4 miles (about $5 \mathrm{~km}$.) to the south. 960 acres of land (about 38,500 sq. decam.) was available, of which 125 acres (about 5,000 sq. decam.) was allocated for the colony. A capital expenditure of $£ 9,000$ was estimated. $£ 3,500$ would be contributed by the Native Authorities and the remainder by BELRA. BELRA would be responsible for the building operations, including the house for the Supervisor, whom they would supply. A further capital grant of $£ 750$ was to be made by the Native Authorities for the purchase of equipment.

In the event, between 1952 and 1955, while the Leprosarium was under construction, $£ 13,000$ was spent on capital works and equipment, of which the Native Authorities contributed $£ 5,500$ and BELRA the remainder.

Three Native Authorities combined in making contributionsthat of Mikandani (Mtwara) District joining the scheme-and all three Authorities were represented by the District Commissioners on the interim Management Committee formed during the construction period. The Supervisor of the U.M.C.A. outpatient scheme and one of the Mission doctors also sat on this committee, as it was envisaged that the Mission could assume clinical charge of the Leprosarium when it was opened to patients.

The main buildings were pre-fabricated, but the residential accommodation for patients was of a semi-permanent nature, built of mud-brick on concrete rafts with corrugated iron roofing. Buildings were in units, holding eight patients each, and consisted of two rooms each housing four patients, with a central verandah.

When construction neared completion, a Board of Visitors was appointed, consisting of:

The District Commissioner from each of the three Districts concerned;

One African representative from each Native Authority contributing;

A representative of the Government Medical Department;

A medical representative of the U.M.C.A.;

A medical representative of the Benedictine Mission.

The Manager of the Leprosarium was to act as Secretary. 
The policy of this Board was to co-ordinate anti-leprosy treatment carried on by all agencies in the three Districts around the Leprosarium. All grants in assistance to outpatient treatment centres would be made through the Mkunya Organisation. Each agency operating treatment centres would continue to be responsible for the administration of its own units and the Board would only intervene in cases of dispute.

The estate account and the medical accounts of the Leprosarium would be administered separately. The working of the estatemainly a cashew-nut plantation-would be the duty of the patients, but outside labour might sometimes be required. Any profit from the estate account would be used for the extension of anti-leprosy units.

The admission of patients from each of the three Districts would be in proportion to the annual maintenance contributions from each. A registration fee of five shillings would be payable by all outpatients receiving treatment under the scheme. Four outpatient centres were planned at this time, including the outpatient clinic at the Leprosarium itself.

The Leprosarium opened in May 1955, with the Manager assuming charge of the day-to-day medical supervision, as well as the running of the estate. It had been found that the Supervisor of the outpatient scheme could not undertake this work, and he remained at Lulindi.

Early in 1956 a memorandum on the future expansion of the scheme was submitted to BELRA. At that time 2,500 outpatients were under treatment in 16 treatment centres, all on sulphone therapy, so that less than a quarter of the 11,058 cases estimated in the three Districts five years before were known to be receiving treatment. The supervision of these outpatient centres was found to be beyond the capacity of one supervisor, so later in the year a second BELRA worker arrived at Mkunya to assume medical charge there, and to assist in the supervision of the outpatient centres.

At the same time it was decided to implement the new general policy with regard to the segregation of patients in leprosaria, consequent upon the proved therapeutic success of the sulphone drugs, and to confine admissions to lepromatous patients, those cases showing a reaction to the sulphone therapy and patients with the tuberculoid form of the disease requiring surgical procedures. Building operations were therefore deferred at a stage when the accommodation was sufficient for 110 residents.

\section{Financial Difficulties}

The cashew crop for 1955 was a poor one; by the middle of 1956 the liquid assets of the Leprosarium were exhausted and an overdraft was negotiated to meet recurrent expenditure until such time 
as the 1956 crop had been sold. The 1956 crop was no better. However, after a contract had been made with a produce dealer, the 1957 crop realised sufficient to cover the costs of running the estate.

Early in 1958, when a new Manager arrived, the accounting system was found to be other than the Board had advised. It was evident that the farm had been run at a loss and that the main crop was less than could be expected from the cashew trees bearing. For the 1958 crop, a bonus system of harvesting was introduced, whereby patients received payment by result in addition to their daily "wage". The farm showed a considerable profit as a result, but even with this addition to the medical account, expenditure exceeded income.

Maintenance of buildings was becoming increasingly expensive and the scheme was committed to the building of three outside permanent clinics, for which a further grant of $£ 1,100$ had been made by BelRA. The Government Agricultural Department reported considerable land erosion on the estate; preventative measures would cost $£ 500$ over a period of three years.

Difficulties arose with the patients also. The withdrawal of credit facilities at the colony's shop caused a strike of the labour force. A limited experiment of issuing rations in lieu of daily wages was tried, but was found to be more expensive and to require extra supervision.

Early in 1959, BELRA suggested subsidising the colony to the extent of $£ 500$ per annum for a period of five years, to assist in getting the Leprosarium 'on its feet' and in further expansion of the work. The Board did not feel able to commit the Leprosarium to increasing recurrent expenditure until the present position could be consolidated. However, three months later, $£ 1,000$ as an outright grant and the first instalment of $£ 500$ for capital expenditure, was received from BELRA.

Before any further expenditure was incurred, a complete survey of the buildings was made and a formidable list of repairs and replacements was presented. The cost of these could not be met, even with the grants, and, after a full account of the position had been compiled, a Committee of Enquiry was set up by the Director of the Government Medical Service. This Committee found that the Leprosarium could remain solvent but with no margin for maintenance of buildings, that the financial future based on expected farm profits would be extremely precarious and that the Leprosarium was not carrying out the function for which it was designed. The Committee expressed the opinion that the total abandonment of leprosy work at Mkunya would be undesirable and suggested that some form of outpatient centre, with or without a resident BELRA worker, should be maintained. 


\section{Mkunya Leprosarium Doomed}

The 1959 cashew crop exceeded expectations and produced the highest income yet achieved. But before the Committee's report had been received by the Board, the elements took a hand in shaping the future of the Leprosarium. On 10th December, 1959, the Makonde Plateau was subjected to a severe tropical depression, with winds of hurricane force, followed by prolonged heavy rain. The Leprosarium lay in the area most severely affected and suffered considerable damage as a result. Few, if any, of the buildings escaped and a considerable number of the cashew trees were uprooted. No habitable accommodation remained for the patients, and there was no alternative but to discharge them to their homes. Some of the cashew trees recovered, however, and harvesting continued into January, 1960.

The recommendations of the Committee of Enquiry were followed in general by the Board. The assets of the Leprosarium were placed for disposal, and after the cost of the replacement of the BELRA worker's worn-out vehicle had been met, the proceeds were divided among the agencies who had met the capital cost, in proportion to their contributions. The work of the Mkunya Board was to continue in the supervision of outpatient treatment facilities, and was to be modified and widened to include facilities provided by the local authorities of other districts willing to come into the scheme.

\section{Discussion}

Ten years have passed since the recommendations on which the Mkunya Leprosy Control Scheme was founded were made. At the time of its inception, the placing of the control of a public health service of this nature in the hands of African local authorities, and relying on their financial support and encouragement, had not been tested. The experiment can be judged to have been successful.

The indigenous population were aware of the unfortunate effects of the disease in an area of such high incidence, its low fatality rate and the considerable disabilities from which its victims suffered. Yet sufferers from leprosy were accepted as part of the community; they lived with their families in the village homes and offered themselves for any treatment which would bring them relief. Their chosen representatives and administrative leaders were generous in providing public funds for treatment schemes. $£ 14,000$ was contributed by three local authorities to the Mkunya funds over a period of seven years, in addition to grants to the Missions and provision for treatment in their own local dispensaries.

The conception of being segregated in a colony was foreign to their nature. It involved separation from their families and from their own land for a period of at least three years, and the treatment provided could, in most cases, be obtained at the nearest dispensary. 
Great persuasion was required before patients would be admitted, and absconding from the colony was not infrequent.

Those admitted were expected to work to be able to live. Such patients as actually wished to be admitted - the 'burnt-out' cases with gross deformity - were turned away because the facilities provided for patients requiring chemo-therapy only; no surgery or physiotherapy was possible at Mkunya. Yet the colony's accommodation was kept full up to the last few months, when admission was restricted for financial reasons.

The settlement was planned before the therapeutic effects of the sulphone drugs had been fully evaluated and their bearing on the policy of segregation fully realised. In the original planning of the scheme, Ross Innes states (personal communication) that the prime reason for his advising the establishment of the colony was not as a centre of segregation, but to raise the standard of the local antileprosy work by the creation of a laboratory, the training of African workers, facilities for research and for the medical treatment of reactions. For this purpose, the colony would have to be expanded to accommodate 1,000 patients with a medical officer, two nursing sisters, a lay supervisor and a laboratory technician heading the resident staff. The estate was developed and planted to provide work for this number of patients, and could not be run economically with the number eventually available, many of whom were disabled by the disease. It could not have become self-supporting under such conditions.

It must also be admitted that both the financial and general administration was placed in the hands of those untrained for it, or engaged in too many other duties to be able to deal with it efficiently. Until 1958 there was not even an African clerk on the Leprosarium staff to assist the Manager, who was also expected to be farmer, mechanic and clerk of works.

The Medical Department of Central Government provided the specific drugs used in the treatment of leprosy free of charge to all institutions providing a treatment service, and for the last two years of the scheme, the author, as the Government District Medical Officer, acted as Visiting Medical Officer to the colony, and assumed a general supervisory capacity over the outpatient treatment centres administered by two of the three local authorities contributing to the scheme. The day-to-day supervision of these centres was carried out by the two BELRA workers.

'There was active and friendly liaison between the various agencies administering the leprosy treatment service, but, except for the control on expenditure of drugs supplied through Government channels, no overall co-ordination of the service. This was one of the functions that it had been intended the Board of Visitors should assume. 
In the pilot stage, which the Leprosarium had reached by the time it ceased to function, no facilities for the confirmation of the diagnosis of the disease type, or for the evaluation of progress in the treatment of patients by laboratory techniques were available, with the exception of simple microscopy from skin smears and the estimation of the haemoglobin levels. The necessity for treatment, and the period of treatment required, was judged almost entirely on clinical grounds.

Further, little or no provision was made for the treatment of the neural forms of the disease, nor for the prevention or correction of the disabilities resulting therefrom. Yet it was these manifestations of the disease which most affected the working capacity and mental outlook of the patients who suffered from them. Such facilities as were available at general hospitals near the Leprosarium were limited by lack of isolation accommodation, and of trained staff, particularly those conversant with physiotherapeutic techniques.

Except for the encouragement of sufferers from the disease in seeking treatment at the centres, little or no education of the patients, or of the general public,was attempted. The African staff at work in these centres had received no training in the educational aspect of their duties, and there was no centre available where such training could be given by example.

\section{General Considerations}

In the present situation, when drugs are available which will control, if not cure, the majority of the infectious cases of leprosy, is the expense involved in the provision of centres for the segregation of infectious cases from the rural areas of under-developed territories justifiable? Ross Innes is of the opinion that the idea of segregation of all patients in institutions must be given up, firstly because it is too expensive and secondly, because it is of doubtful value; but a focus of hospitalization, special care, research and training is needed in strategic areas. W.H.O. (1958) states: "Leprosy patients no longer tend to avoid treatment because of its possible association with segregation. They now come forward spontaneously". Although the drugs can produce an acute leprotic neuritis, which is destructive if not treated, mass treatment is feasible, especially when bi-monthly intramuscular injections of D.D.S. suspension in chaulmoogric media are used.

On the other hand, Cochrane (1959) gives a warning "that it is a dangerous form of wishful thinking to consider that the control of leprosy can be achieved by pressing for more and more treatment centres without adequate regard for other preventative measures". He points out that statistics have shown that only in certain areas in the world has there been a general decline in the incidence of leprosy, while in other areas there has been an apparent increase, 
despite intensive treatment campaigns. Because of the failure, to date, to isolate and culture the infective organism, the study of the epidemiology of the disease has been severely limited, and such studies as have been made have shown considerable variations throughout the world. From studies in the United States, Badger (1959) concludes that leprosy is as contagious or more contagious than is poliomyelitis. Like the latter disease, however, few of the persons infected present with clinical evidence of the disease. The period of incubation has yet to be accurately determined. It is apparent that leprosy is transmitted by direct contact, and, contrary to previous belief, this contact does not have to be unduly repetitive nor over a long period. The contact has to be with an infective case, and as pathological investigations have become more accurate and discriminatory, it has been shown that more cases are infective and remain infective over longer periods than was previously thought.

If, then, segregation is to be an essential part of the leprosy control programme, to what extent can adequate provision be made commensurate with reasonable cost? Cochrane stresses that adequate control measures must be related to the general public health service, as has been done in the case of the prevention of tuberculosis, syphilis, sleeping sickness and malaria. The sympathy of the whole medical profession must be enlisted and the services of para-medical personnel utilised. Specialists will be needed to advise the public health service, but should not form a special cadre of officers, except where there is a need for a limited number of special clinics and hospitals. The fundamental principle, he states, is accepted by all, that leprosy control and treatment is an inescapable responsibility of the national government.

Ekambaram and Sharma (1958) describe a small centre in South India and compare the methods used there. with those in Nige ria Ceylon, Siam and Malaya. They came to the conclusion that the problem could only be solved if tackled together with the treatment and control of other diseases, and not as a isolated entity. Segregation is practical only insofar as it is possible in the patient's own home; both the treatment teams and the public health staff educate the public on the nature of leprosy and its prevention, laying special emphasis on the protection of the children.

Mallac (1960) gives a two-year assessment of a control scheme in the Gambia, based on village treatment clinics. The need for a focal leprosarium is stressed where the sequelae of the neural type of the disease can be treated, as well as all the reactive cases. No segregation methods are attempted.

Kinnear Brown $(1952,1956,1957,1960)$ describes the evolution of leprosy control in Uganda. The need for adequate local survey is stressed, and the evolution of special treatment villages is des- 
cribed. These provide a measure for segregation in combination with treatment of the infective patient. Again the necessity for a leprosarium for the treatment of the disability of the individual patient is stressed. He is the unit who unconsciously, controls the destiny of the control campaign, and his confidence must be gained. The centre also provides the focus for the training of the therapist, both in the social background of the patient, as well as in the treatment of his disease.

Wheate $(1957,1960)$ describes a small control scheme centred on a leprosarium in the Southern Highlands of Tanganyika, where the associated outpatient treatment centres were administered by the African local authority, under the supervision of the medical officer of the leprosarium.

\section{Conclusions}

Health and education services consume a considerable proportion of the national expenditure of emerging states, such as Tanganyika, but the proportion of the allocations on health services which can be devoted to the control of a disease such as leprosy is very limited, when there are many other urgent requirements to receive priority. Nevertheless, it is felt that too little attention has been directed towards this disease in the past. Two main reasons are suggested. Firstly, the low mortality rate, and the failure to recognise the disablement caused by the neural form of the disease, have placed it low in the priorities of international health control programmes. States which rely on the advice and assistance of the World Health Organisation and its special agencies have felt, therefore, that they would elicit little sympathy in embarking on comprehensive control measures.

Secondly, the study of this disease is attractive to few of the medical profession, and its advocates are also few. There are eminent authorities throughout the world, but, on average, such control measures as are undertaken by the undeveloped countries are placed in the hands of enthusiasts with little training in the specialty, and who have to reach proficiency by their own experience. Much could be gained by the scientific study of the disease in a co-ordinated and intensive manner at centres where officers assuming charge of control schemes could be trained in the scientific disciplines of diagnosis, including pathological aids, and in the statistical assessment of the disease incidence and the effect of control measures on such incidence.

Local surveys are of the utmost importance before any expenditure is incurred; the absence of the most elementary vital statistics in undeveloped areas makes this a slow and laborious process. Yet the planning of local control measures must be based on accurate incidence trends, so that the resulting treatment schemes 
are not overloaded, and hampered by financial and staffing shortages. The conduct of such surveys, and the general overall supervision of the control measures instituted, should remain the responsibility of the national health service, and would require the allocation of a special cadre of medical officer and ancillary staff in the first instance. In areas of low incidence and where the proportion of infective cases to the total leprosy patients is low, the resultant control scheme could well be integrated with the general public health and therapeutic services, with overall control by a specialised officer. The district general hospitals would then provide inpatient accommodation for the treatment of the simpler complications and sequelae of the disease, together with limited isolation facilities for the infectious cases.

In areas of high incidence-and the area in which the Mkunya scheme has been operating would be classified as such - the necessity for a special residential treatment centre is still apparent, despite the advances made by the advent of the sulphone compounds. Not only would such a centre provide for the segregation of the infectious cases, but it would also be the focus for the prophylaxis and treatment of the disabilities resulting from the disease. In addition, it would serve as a training centre for the staff engaged in the treatment, in the social welfare and in the health education of the patients, as well as the education of the general public. A centre of this nature should also be the responsibility of the national government. Patients should be accommodated and treated free of charge, and be given a small reward for the product of their work in the rehabilitation side of the treatment. Attached to such a centre, there should be a training centre, where disabled patients could be taught new skills, so that when they are discharged to their homes, they could become active members of the community and no longer a burden on their relatives nor the object of public philanthropy. The residential centre would need to be equipped with facilities and staff for the operative surgery of the nerve and bone lesions, for remedial physiotherapy and for the special pathological techniques involved in the diagnosis and the assessment of progress - these last including facilities for histo-pathology.

In both low and high incidence areas, the treatment of the non-infective patient without potential or actual disability should be the responsibility of the local authorities; such village treatment centres would be supervised by the staff of the residential centres or local general hospital, and be manned by personnel trained in the detection of the various clinical types of the disease and the prophylaxis of the early disability or potential disability. In low incidence areas, the village centre could well be accommodated in the general dispensary, but where a large number of patients was anticipated, special buildings within the enclave of the general health 
centre would be required and the specially trained staff employed full-time.

Public health staff should receive a limited training in the epidemiology of the disease, so that instruction in its prevention could be given individually and to village groups in the course of their routine work. In areas of high incidence, special public health staff would need to be trained and allocated specifically to leprosy control duties, engaged in case detection, including the follow-up of contacts and in specific health education programmes.

It is obvious from the above, that the areas covered by such control measures would be limited by their cost. With technical and financial assistance available from the international agencies, these would not of necessity be limited in size. When requests for assistance are made, the greatest stress should be placed on the need for trained staff, especially in the para-medical field. Although leprologists and surgeons acquainted with the neural and orthopaedic complications of the disease are sadly lacking, the need for the physiotherapist, the laboratory technician, the occupational therapist and the trained social worker is even more urgent. Not only the patient of today, but the local staff to be trained by them for the continuation of the scheme tomorrow, require their help. It is in this field that such organisations as BELRA could concentrate their energies.

And what of the voluntary agencies, such as the Missions, who have done so much in the treatment of the leprous patient in the past? The problem is a national one; the disciplines, of its control become more complex and beyond the resources of the majority of such agencies. Their help is urgently needed, but should be directed under a national policy and under closer national supervision and co-ordination. The patient, if he is to be attracted to receive the full benefit of the scheme, should be offered not only the drugs, but all the other known beneficial methods of treatment, and these should be standardised and be adaptable as research and experience provide further benefits. In the final event it is the patient who will determine the success or failure of any public health control scheme.

"No organisation controled by the State can do more than exert a favourable influence upon a subject so personal and so intimate as the health of the individual. The main influence will continue to be exerted by the individual himself through the habits and customs of his daily life, affected as they are by his intelligence, education and environment. The State has, however, its important part to play. It can provide a favourable environment both in the home and in the factory; it is able, within limits dictated by economic and political circumstances, to influence for the better the standard of living of the worker; and it is within its competence to secure for 
him in old age or sickness the means whereby he can continue to live a satisfactory life.

"It is necessary to emphasise the fact that these desirable provisions which influence so much the health of the worker, can only be made by a highly-organised State which has at its command very great resources, and which possesses competent central and local government machinery adapted for this purpose". Fraser (1950).

\section{Summary}

The story of the five years' experience of a pilot leprosy control scheme in Southern Tanganyika has been described. The scheme was an experiment in that the administrative control and the financial backing was placed in the hands of a Board of Visitors representing three African local authorities, with the assistance of the British Leprosy Relief Association and two Missionary organisations. The supervision of the medical service of the national government was kept to a minimum. The original function of the scheme was not realised.

An assessment of the success or failure of the scheme is made. Reports of some recent limited leprosy control schemes throughout the world, but especially in the African continent, are reviewed and the basic principles of control measures in an emerging undeveloped State with limited financial resources, suggested.

I wish to thank the Board of Visitors to Mkunya Leprosarium, who gave me access to the records of the institution since its inception, to the Medical Secretary of BELRA for his advice and encouragement, and to the Director of Medical Services, Tanganyika, for permission to publish this paper.

\section{References}

BADGer, L. F., "Leprosy in Theory and Practice", edited by R. G. Cochrane (1959). John Wright (Bristol).

Cochrane, R. G., "Leprosy in Theory and Practice" (1959). (1959). John Wright (Bristol).

Ekambaram, V. and Sharma, C. S. G., "Leprosy Relief and Control Work in Tirukoilur, South India" (1958). Leprosy Review, Vol. 29.

Fraser, W. M., "A History of English Public Health 1834-1939" (1950). Balliere, Tyndall \& Cox, London.

Kinnear Brown, J. A., "Leprosy in Uganda" (1952). E.A.M.J., Vol. 29. " "The Uganda Leprosy Control Scheme" (1956), E.A.M.J., Vol. 33. "Leprosy Control in Rural Areas" (1957), E.A.M.J., Vol. 34. Vol. 31 .

"Mass Campaigns and the Individual" (1960), Leprosy Review,

MallaC, M. J., "Aspects of Leprosy Control in the Gambia, B.W.A." (1960), Leprosy Review, Vol. 31.

Ross INNES, J., "Leprosy in Tanganyika" (1950), E.A.M.J., Vol. 27.

WhEATE, H. W., "A Small Scale Leprosy Control Scheme in Rungwe District, Tangayika" (1957), E.A.M.J., Vol. 34.

"An Example of Leprosy Control in Tanganyika" (1959). Appendix X to "Leprosy in Theory and Practice", edited by R. G. Cochrane (q.v.).

W.H.O., "The First Ten Years of the World Health Organisation" (1958), W.H.O., Geneva. 